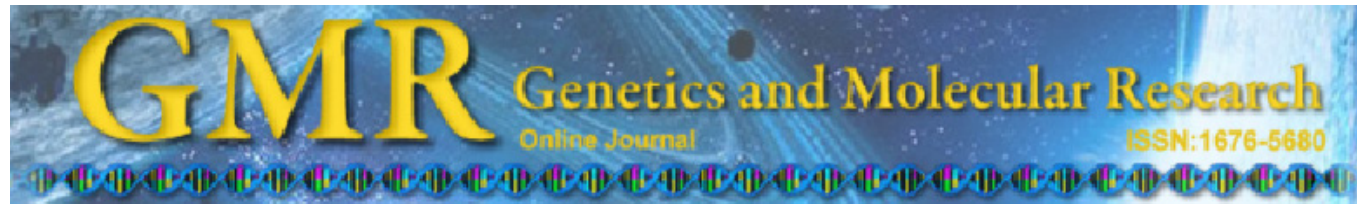

\title{
Effect of pregnancy on the genetic evaluation of dairy cattle
}

\author{
R.J. Pereira1, M.L. Santana Jr. ${ }^{2}$, A.B. Bignardi' ${ }^{1}$ R.S. Verneque ${ }^{3}$, \\ L. EI Faro ${ }^{4}$ and L.G. Albuquerque ${ }^{1}$
}

'Departamento de Zootecnia, Faculdade de Ciências Agrárias e Veterinárias, Universidade Estadual Paulista "Julio de Mesquita Filho", Jaboticabal, SP, Brasil

${ }^{2}$ Instituto de Ciências Agrárias e Tecnológicas, Universidade Federal de Mato Grosso, Rondonópolis, MT, Brasil

${ }^{3}$ Embrapa Gado de Leite, Juiz de Fora, MG, Brasil

${ }^{4}$ Agência Paulista de Tecnologia dos Agronegócios, Secretaria de Agricultura e Abastecimento, Ribeirão Preto, SP, Brasil

Corresponding author: R.J. Pereira

E-mail: rodjunper@yahoo.com.br

Genet. Mol. Res. 10 (3): 2190-2201 (2011)

Received November 16, 2010

Accepted February 01, 2011

Published September 26, 2011

DOI http://dx.doi.org/10.4238/vol10-3gmr1151

ABSTRACT. We investigated the effect of stage of pregnancy on
estimates of breeding values for milk yield and milk persistency in
Gyr and Holstein dairy cattle in Brazil. Test-day milk yield records
were analyzed using random regression models with or without the
effect of pregnancy. Models were compared using residual variances,
heritabilities, rank correlations of estimated breeding values of bulls and
cows, and number of nonpregnant cows in the top 200 for milk yield and
milk persistency. The estimates of residual variance and heritabilities
obtained with the models with or without the effect of pregnancy were
similar for the two breeds. Inclusion of the effect of pregnancy in genetic
evaluation models for these populations did not affect the ranking of
cows and sires based on their predicted breeding values for $305-$ day
cumulative milk yield. In contrast, when we examined persistency of 
milk yield, lack of adjustment for the effect of pregnancy overestimated breeding values of nonpregnant cows and cows with a long days open period and underestimated breeding values of cows with a short days open period. We recommend that models include the effect of days of pregnancy for estimation of adjustment factors for the effect of pregnancy in genetic evaluations of Dairy Gyr and Holstein cattle.

Key words: Days open; Lactation curves; Random regression model; Stage of pregnancy

\section{INTRODUCTION}

Two important functions that guarantee the survival of mammalian species are attributed to pregnancy: the first is to provide protection, nutrition and an adequate environment for fetal development, and the second is to promote the development of the mammary gland, which is necessary for feeding of the newborn.

It is believed that a dairy cow should calve at intervals of 12 months to optimize cumulative milk yield during useful life, providing maximum economic return of the enterprise. However, the cow is exposed to an exceptional physiological situation during pregnancy, which may compromise milk production because of regression of the mammary gland especially in the last third of pregnancy and of nutrient competition for fetal development (Erb et al., 1952; Bachman et al., 1988; Brotherstone et al., 2004; Akers, 2006). Milk production is affected by pregnancy, especially after the fifth month when the nutritional requirements of the fetus increase (Olori et al., 1997; Roche, 2003; Bohmanova et al., 2009). Bohmanova et al. (2008) reported milk production losses due to pregnancy ranging from 1.9 to $3.8 \%$ for five dairy cattle breeds.

According to Haile-Mariam et al. (2003), ignoring the effect of the stage of pregnancy in genetic evaluations based on test-day milk yield (TDMY) may overestimate production at the beginning of lactation and underestimate it at the end of lactation, leading to non-genetic differences between animals and reducing the accuracy of the prediction of breeding values. Therefore, several countries have performed genetic evaluations taking into account the previous days open or stage of pregnancy (Interbull, 2010) in an attempt to prevent or reduce selection bias due to this effect.

Several studies including those cited above have identified and quantified the effects of pregnancy on the production of milk and its components, but few have investigated the consequences of including or not these effects in genetic evaluations for the purpose of selection. Particularly in Brazil, the effect of pregnancy is not included in most genetic evaluation programs of dairy cattle. Therefore, the objective of the present study was to evaluate the effect of stage of pregnancy on variance components and estimated breeding values for milk yield and milk persistency in Dairy Gyr and Holstein cattle in Brazil.

\section{MATERIAL AND METHODS}

\section{Dairy Gyr}

A total of 18,385 TDMY records from 2292 first lactations of Brazilian Dairy Gyr cows, 
daughters of 347 sires that calved between 1990 and 2007 in 52 herds, were used. The age at calving ranged from 24 to 60 months. The data were obtained from the National Animal Science Archive, managed by the National Center for Dairy Cattle Research (Embrapa Gado de Leite). The predominant production system of Dairy Gyr herds consists of pasture plus concentrate supplementation according to production during the rainy season and roughage supplementation (sugarcane and urea) during the dry season.

\section{Holstein}

A total of 17,599 TDMY records from 1011 first lactations of Holstein cows, daughters of 174 sires that calved between 1997 and 2004, were used. The age at calving ranged from 20 to 45 months. The data were obtained from one herd in the State of São Paulo. In this herd, the animals are housed in free-stall confinement and feed consists of corn silage, pre-dried Tifton grass silage and Tifton hay plus concentrate supplementation according to production throughout the year.

\section{Data consistency}

Test-day records from day 5 to day 305 of lactation were used. The following criteria were established for inclusion of the cows in the study: first test-day record obtained up to 45 days after calving and the number of test-day records more than three (Dairy Gyr) or four (Holstein). In addition, the contemporary group (CG), defined as herd-year-month (Dairy Gyr) or year-month (Holstein) of test, should contain at least three cows. The TDMY records were divided into 10 (monthly, Dairy Gyr) or 20 (biweekly, Holstein) classes of days in milk and cows with milk yields above or below three standard deviations of the average of the classes of days in milk were eliminated from the analysis.

The conception date was estimated as the date of second calving minus average gestation length, which is assumed to be 286 days. The number of days pregnant (DP) on the test-day was calculated as conception date minus test date.

Nine classes of stage of pregnancy were defined: P0 (nonpregnant cows), P1 (1 $\leq \mathrm{DP} \leq 30), \mathrm{P} 2(31 \leq \mathrm{DP} \leq 60), \mathrm{P} 3(61 \leq \mathrm{DP} \leq 90), \mathrm{P} 4(91 \leq \mathrm{DP} \leq 120), \mathrm{P} 5(121 \leq \mathrm{DP} \leq$ $150)$, $\mathrm{P} 6(151 \leq \mathrm{DP} \leq 180)$, $\mathrm{P} 7(181 \leq \mathrm{DP} \leq 210)$, and $\mathrm{P} 8$ (DP $\geq 211)$. For the Dairy Gyr breed, classes P7 and P8 were analyzed together because of the small amount of data.

\section{Models}

TDMY were analyzed using random regression models that included CG, DP and age at calving as fixed effects, and additive genetic and permanent environmental effects of the animal as random effects. Residual variances were considered to be heterogeneous and were divided into classes as follows: 1st, 2nd-6th, 7th-10th, 11th-17th, 18th-19th, and 20th fortnight of lactation for Holstein animals, and 1st, 2nd, 3rd, 4th-6th, 7th-9th, and 10th month of lactation for Dairy Gyr animals.

The general random regression model used in the analyses including the effect of pregnancy can be described as: 


$$
y_{i j k l}=C G_{i}+P_{j}+\sum_{n=1}^{2} b_{n} x_{i k}+\sum_{m=0}^{o_{b}-1} \beta_{m} \varphi_{m}(t)+\sum_{m=0}^{o_{a}-1} \alpha_{k m} \varphi_{m}(t)+\sum_{m=0}^{o_{p}-1} p_{k m} \varphi_{m}(t)+e_{i j k l} \quad \text { (Equation 1) }
$$

where $y_{i j k l}$ is the $l^{\text {th }}$ observation recorded on lactation day $t$ of cow $k$ in $C G i$ and class of stage of pregnancy $j ; C G_{\mathrm{i}}$ is the effect of the $i^{\text {th }} \mathrm{CG} ; P_{j}$ is the effect of the class of stage of pregnancy $j ; b_{n}$ is the regression coefficient for linear $(\mathrm{N}=1)$ and quadratic $(\mathrm{N}=2)$ effects of age $x_{i k}$ of cow at calving, in months; $\beta_{m}$ is the set of $m$ fixed regression coefficients for the mean trajectory of the population; $\varphi_{\mathrm{m}}(\mathrm{t})$ is the covariate of the regression functions of orders $o_{b}, o_{a}$, and $o_{p}$ according to lactation day $(\mathrm{t}) ; \alpha_{k m}, p_{k m}$ are sets of $m$ additive genetic and permanent environmental regressors for each cow $k ; o_{b}, o_{a}$ and $o_{p}$ are the orders of the linear functions used to describe the mean trajectory of the population and the additive genetic and permanent environmental random effects of the cows, respectively; $e_{i j k l}$ is a random error or temporary measurement error associated with observation $l$ of cow $k$ belonging to CG $i$ and class of stage of pregnancy $j$. Legendre polynomials of orders 4, 5 and 5 (Dairy Gyr) and 4, 6 and 7 (Holstein) were used for fixed $\left(o_{b}\right)$, additive genetic $\left(o_{a}\right)$ and permanent environmental $\left(o_{p}\right)$ regressions.

The model without the effect of pregnancy contained all effects of the preceding model, except for the effect of stage of pregnancy class $\left(P_{j}\right)$.

Covariance components were estimated by the restricted maximum likelihood method using the WOMBAT program (Meyer, 2007).

\section{Comparison of the models}

The effect of inclusion or not of stage of pregnancy class in the models on genetic parameter estimates was evaluated. In addition, the rankings of the animals according to their breeding values for 305-day cumulative milk yield and persistency of milk yield predicted with the two models were compared. The breeding values for milk persistency during lactation were calculated as the difference between breeding values predicted for month 9 and month 2 of lactation. The percentage of cows and sires in common, i.e., animals that would be selected by the two models when different selection intensities were employed, was calculated based on the breeding values of these two traits. In addition, the models were compared by residual variance.

\section{RESULTS AND DISCUSSION}

Table 1 shows the proportional distribution of TDMY records, average days in milk and average milk yield of the nine stage of pregnancy classes. A higher concentration of data was observed for early stages of pregnancy as expected. Bohmanova et al. (2009), using data from Canadian Holstein cows, found a proportional distribution of TDMY records in monthly stage of pregnancy classes similar to that observed in the present study for Holstein animals. However, average days in milk and milk yield were higher and lower, respectively. Loker et al. (2009a), who studied the effect of pregnancy on production traits of four Canadian dairy breeds, also reported a proportional distribution of TDMY records (Ayrshire breed, mean of three lactations) similar to that obtained in the present study for Holstein cows. In the present 
study, there was a difference between the two breeds, with the observation of a higher concentration of production records in class P0 (nonpregnant) for Dairy Gyr cows. One possible explanation for this finding is that the production data of the Holstein breed originated from only one commercial herd with excellent management practices, whereas the data of the Dairy Gyr breed were obtained from various herds with different management practices. Therefore, it is reasonable to assume that the reproductive efficiency of the Dairy Gyr herds together is lower than that of the Holstein herd. In addition, many Dairy Gyr breeders have delayed the insemination or breeding of their cows because they believe that a decline in milk production occurs after conception, a fact that would compromise the marketing of their herds, which addresses higher yields. The two breeds also differed markedly in terms of average milk yield. This finding could be explained by the substantial difference in management practices and by the shorter period of selection to which the Dairy Gyr breed had been submitted.

\begin{tabular}{|c|c|c|c|c|c|c|}
\hline \multirow[t]{2}{*}{ Stage of pregnancy class } & \multicolumn{3}{|c|}{ Dairy Gyr } & \multicolumn{3}{|c|}{ Holstein } \\
\hline & $\%$ & DIM & MY (kg) & $\%$ & DIM & MY $(\mathrm{kg})$ \\
\hline P0 & 69.9 & 116 & 9.4 & 44.4 & 92 & 29.3 \\
\hline P1 & 7.5 & 175 & 8.7 & 9.3 & 125 & 31.5 \\
\hline P2 & 6.7 & 194 & 8.4 & 8.8 & 150 & 32.2 \\
\hline P3 & 5.5 & 211 & 8.0 & 8.2 & 175 & 32.4 \\
\hline P4 & 4.4 & 229 & 7.8 & 7.8 & 199 & 31.5 \\
\hline P5 & 3.1 & 246 & 7.2 & 7.3 & 223 & 29.9 \\
\hline P6 & 1.9 & 261 & 6.7 & 6.6 & 246 & 28.7 \\
\hline P7 & $0.9^{*}$ & $274 *$ & $6.4^{*}$ & 5.6 & 267 & 25.9 \\
\hline P8 & - & - & - & 2.1 & 278 & 23.0 \\
\hline
\end{tabular}

*Grouping of P7 and P9 classes.

The average lactation curves of cows with different days open (days from calving to conception) obtained after adjusting milk yields for the effects of CG and age at calving are shown in Figure 1 (Dairy Gyr) and Figure 2 (Holstein). In general, the largest difference between curves was observed around month 6 (Dairy Gyr) and month 5 (Holstein) of lactation. Cows with a longer days open showed a lower decline in milk yield in the last third of lactation, indicating that pregnancy reduces milk persistency. An unexpected increase (4\%) in milk yield from month 9 to month 10 of lactation was observed for Dairy Gyr animals with days open of 60 days or less (DO1). This finding may be explained by the fact that lactation should have ceased until month 9 of lactation in most cows of this days open class. As a consequence, mainly animals with a higher milk production potential remained for the calculation of average yield in month 10, thus increasing average milk yield. For Holstein cows, a small increase (1\%) in average milk yield was observed for days open classes DO6, DO7 and DO8, which was possibly a casual finding. Average milk yields after the 9th fortnight were lower in Holstein cows with days open longer than 270 days or nonpregnant cows than in most animals of the other classes (Figure 1). According to Bohmanova et al. (2009), the nonpregnant class may contain animals with health problems, producing less milk and having difficulty in conceiving. 


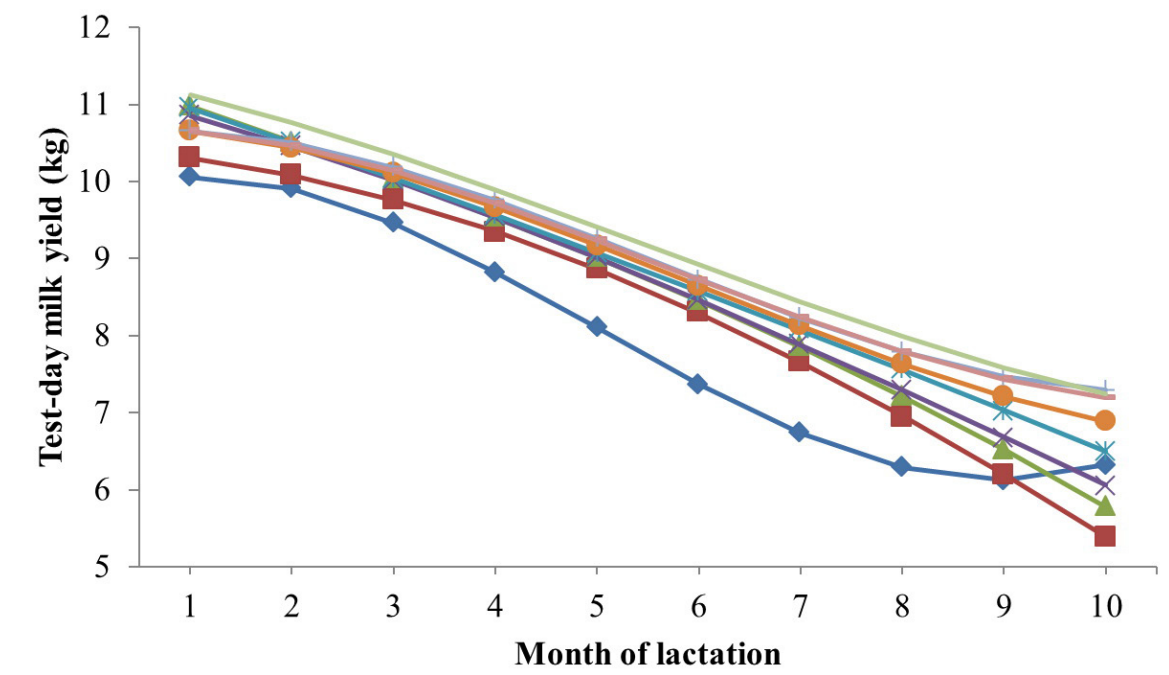

$\because \mathrm{DO} 1 \leftarrow \mathrm{DO} 2 \div-\mathrm{DO} 3 * \mathrm{DO} 4 \div \mathrm{DO} 5-\mathrm{DO} 6 \div \mathrm{DO} 7-\mathrm{DO} 8-\mathrm{DO} 9$

Figure 1. Average lactation curves of Dairy Gyr cows with days open of 60 days or less (DO1), from 61 to 90 days (DO2), from 91 to 120 days (DO3), from 121 to 150 days (DO4), from 151 to 180 days (DO5), from 181 to 210 days (DO6), from 211 to 240 days (DO7), from 241 to 270 days (DO8), and longer than 270 days or nonpregnant cows (DO9).

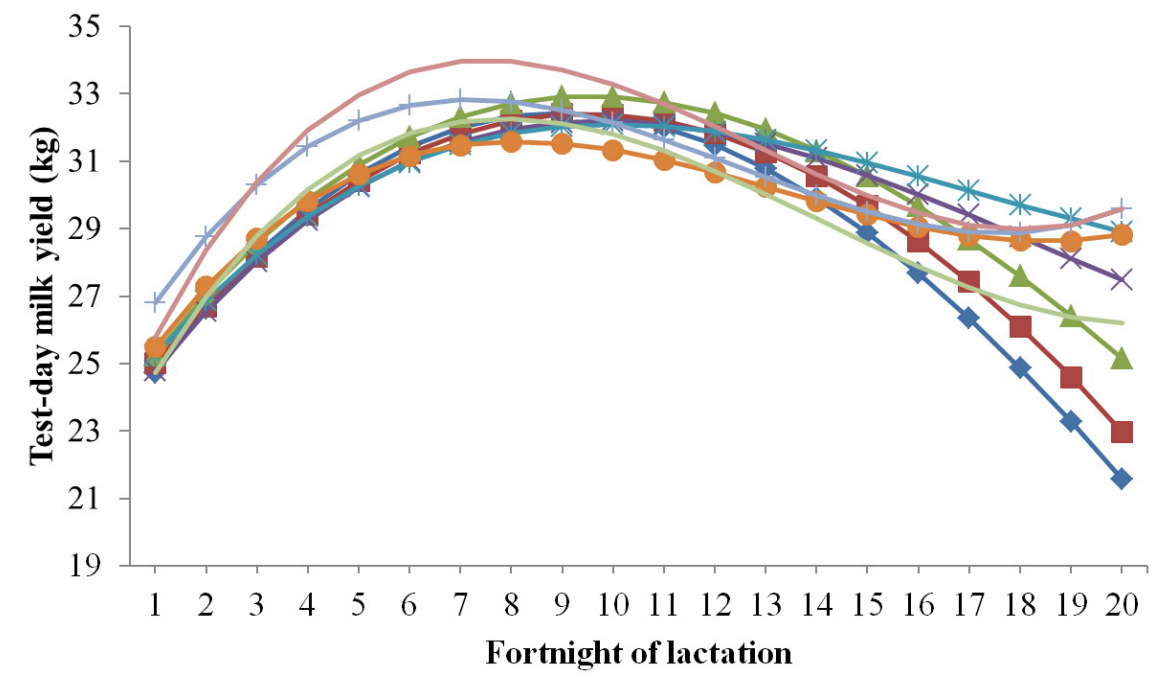

$$
\prec \text { DO1 } \neg \text { DO2 } \leftarrow \text { DO3 } \leftarrow \text { DO4 * DO5 -DO6 -DO7 DO8 DO9 }
$$

Figure 2. Average lactation curves of Holstein cows with days open of 60 days or less (DO1), from 61 to 90 days (DO2), from 91 to 120 days (DO3), from 121 to 150 days (DO4), from 151 to 180 days (DO5), from 181 to 210 days (DO6), from 211 to 240 days (DO7), from 241 to 270 days (DO8), and longer than 270 days or nonpregnant cows (DO9). 
Figure 3 shows the mean percentages of monthly declines in milk yield after peak lactation for cows with different days open. Peak production was observed in the first month of lactation for Dairy Gyr cows and in the fifth month for Holstein animals. As expected, cows with shorter days open showed higher rates of decline in milk yield after peak lactation, although the differences were of small magnitude. This trend of a greater rate of decline in milk yield with decreasing days open was similar for the two breeds.

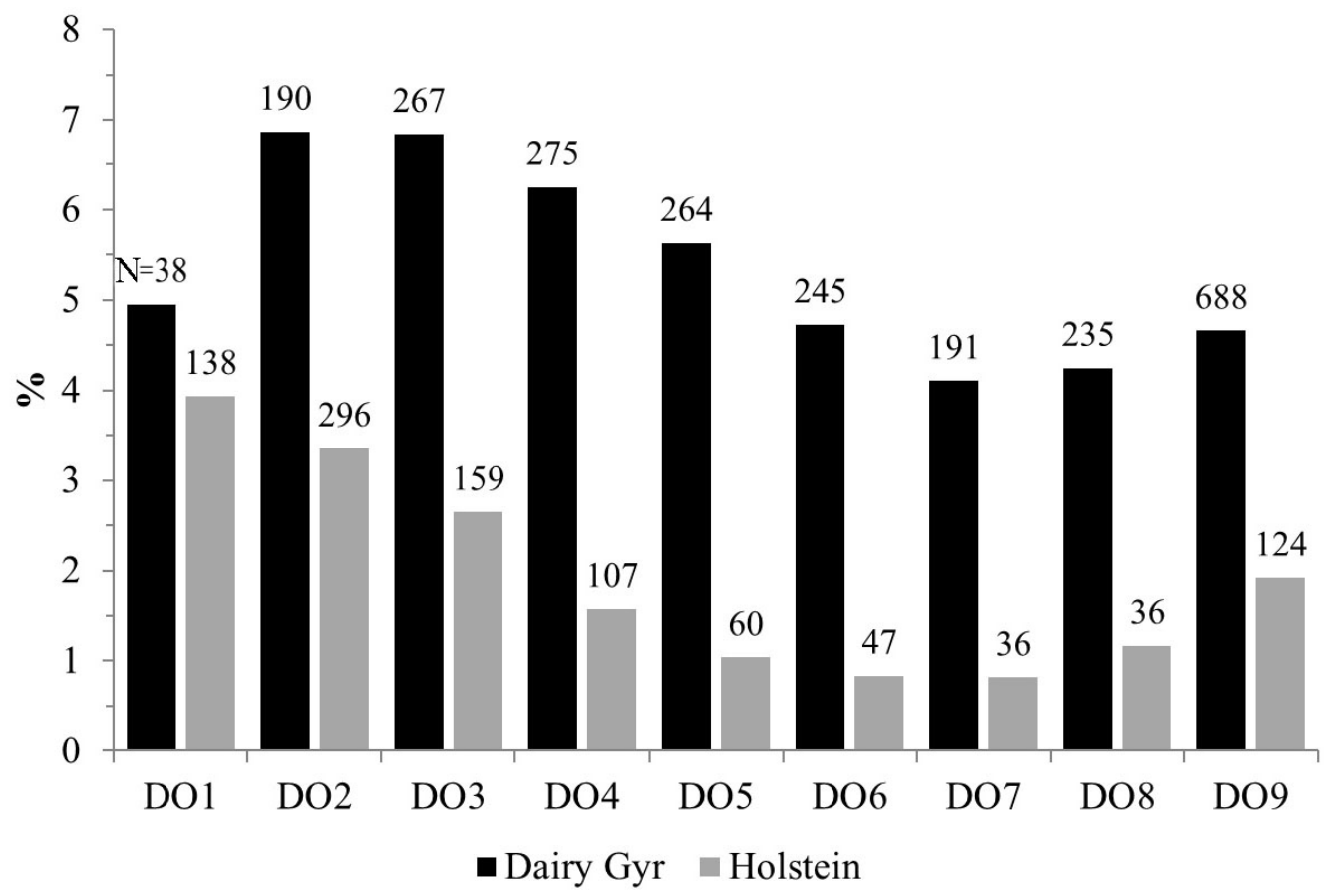

Figure 3. Average percentages of monthly declines in milk yield after peak lactation for cows with days open of 60 days or less (DO1), from 61 to 90 days (DO2), from 91 to 120 days (DO3), from 121 to 150 days (DO4), from 151 to 180 days (DO5), from 181 to 210 days (DO6), from 211 to 240 days (DO7), from 241 to 270 days (DO8), and longer than 270 days or nonpregnant cows (DO9).

The estimates of residual variance (Figure 4) obtained with the two models (with or without the effect of pregnancy) for the two breeds were closely similar, indicating a similar fit of the models. These results differ from those reported by Haile-Mariam et al. (2003) and Bohmanova et al. (2009), who found similar residual variances in mid lactation but higher residual variances at the beginning and end of lactation if the effect of pregnancy was ignored.

The heritability estimates for milk yield and their respective sampling errors are shown in Table 2. Similar estimates were obtained with the models with or without the effect of pregnancy, a fact indicating that the lack of inclusion of this effect did not affect the estimates of covariance components. These results agree with Loker et al. (2009b), who studied data of milk, fat and protein yield and somatic cell count preadjusted or not for the effect of pregnancy in Canadian Ayrshire cows. The authors found no significant difference in genetic parameters between the two data sets. 

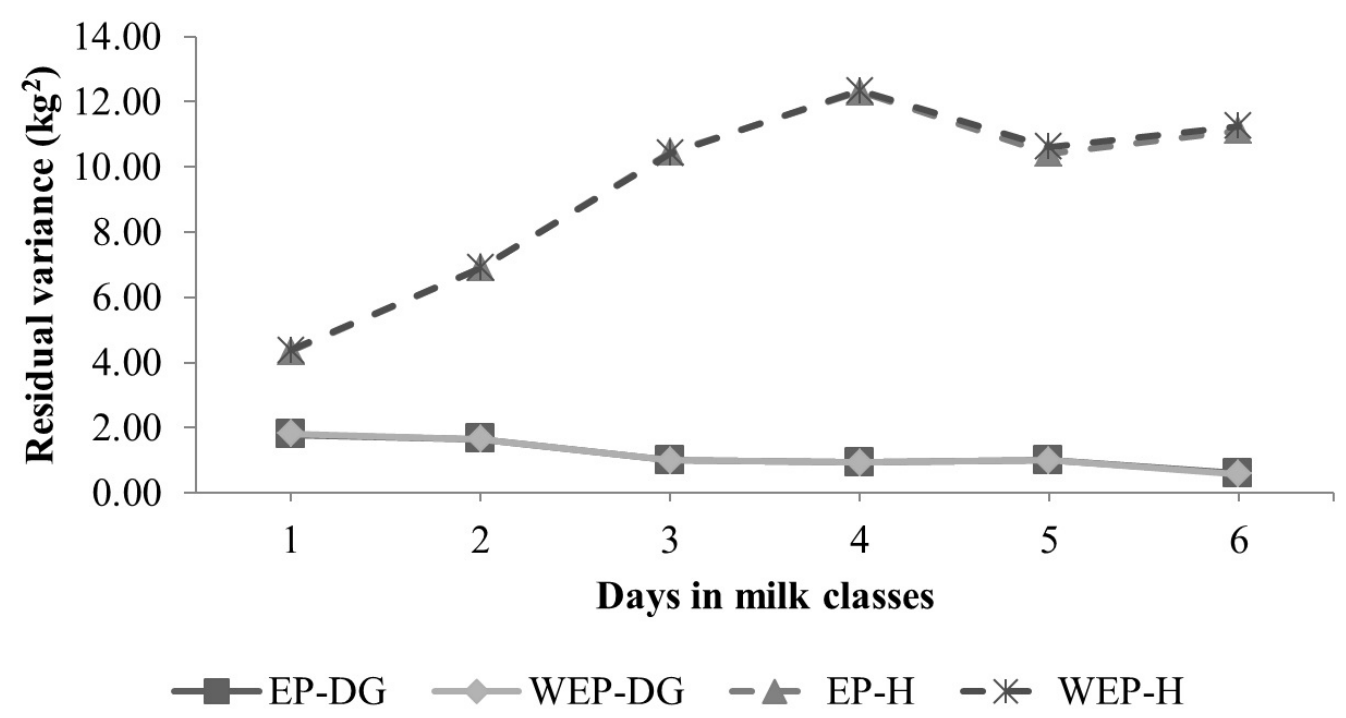

Figure 4. Trend of residual variance across lactation for milk yield estimated by different models: EP-DG = model with the effect of pregnancy - Dairy Gyr; WEP-DG = model without the effect of pregnancy - Dairy Gyr; EP-H = model with the effect of pregnancy - Holstein, and WEP-H = model without the effect of pregnancy - Holstein.

The Spearman rank correlations between breeding values for 305-day cumulative milk yield obtained with the models with and without the effect of pregnancy were 0.997 and 0.996 for Dairy Gyr sires and cows, respectively, and 0.997 for Holstein sires and cows. Therefore, adjustment for the effect of pregnancy is expected to have a small effect on predicted breeding values for this trait. On the other hand, for persistency of milk yield, the correlations were 0.982 and 0.986 for Dairy Gyr sires and cows, respectively, and 0.982 and 0.977 for Holstein sires and cows, indicating that reranking of the animals can be expected if the effect of pregnancy is included in genetic evaluations. Bohmanova et al. (2009), studying the effect of pregnancy on production traits of Canadian Holstein cows, also found high rank correlations between models with and without the effect of pregnancy (0.994) for milk yield and lower correlations $(0.968)$ for milk persistency. The authors concluded that adjusting for the effect of pregnancy has a small effect on predicted breeding values for milk yield, but that a larger effect is expected for milk persistency.

Table 3 shows the percentage of sires and cows in common when different proportions of individuals are selected for 305-day cumulative milk yield or persistency of milk yield using the models with and without the effect of pregnancy for genetic evaluation of the animals. As expected, based on the rank correlations, there was no significant difference between models, with the percentage of animals in common always being higher than $92 \%$. Slightly lower percentages of sires and cows in common were obtained when different proportions of individuals are selected for milk persistency (Table 3) using the two models (with or without the effect of pregnancy), indicating the possible occurrence of changes in ranking when the effect of pregnancy is not included in the genetic evaluations. 
R.J. Pereira et al.

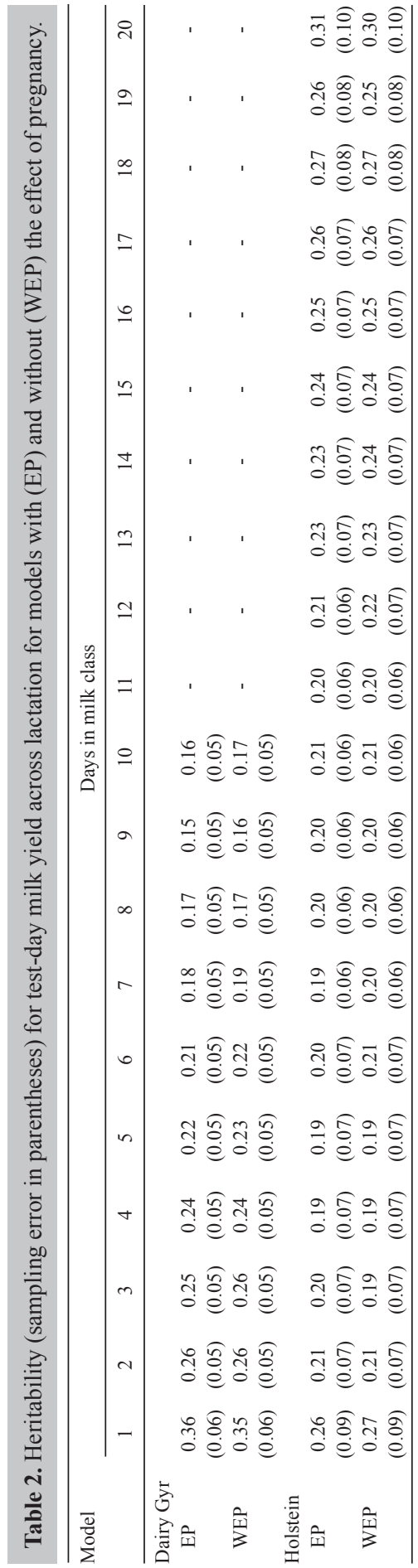


Table 3. Percentage of sires and cows in common when different proportions of individuals are selected (b\%) for 305-day cumulative milk yield (305-day yield) or persistency of milk yield (Persistency) using the models with and without the effect of pregnancy for genetic evaluation of the animals.

\begin{tabular}{|c|c|c|c|c|c|c|c|c|}
\hline \multirow[t]{3}{*}{$\mathrm{b}(\%)$} & \multicolumn{4}{|c|}{ Dairy Gyr } & \multicolumn{4}{|c|}{ Holstein } \\
\hline & \multicolumn{2}{|c|}{ 305-day yield } & \multicolumn{2}{|c|}{ Persistency } & \multicolumn{2}{|c|}{ 305-day yield } & \multicolumn{2}{|c|}{ Persistency } \\
\hline & S\% & $\mathrm{C} \%$ & $\mathrm{~S} \%$ & $\mathrm{C} \%$ & S\% & $\mathrm{C} \%$ & S\% & $\mathrm{C} \%$ \\
\hline 1 & 92 & 96 & 100 & 87 & 100 & 99 & 100 & 89 \\
\hline 5 & 92 & 95 & 100 & 87 & 95 & 97 & 80 & 83 \\
\hline 10 & 92 & 95 & 92 & 89 & 95 & 94 & 90 & 81 \\
\hline 20 & 96 & 97 & 87 & 91 & 95 & 94 & 90 & 90 \\
\hline 40 & 96 & 97 & 89 & 94 & 95 & 97 & 95 & 91 \\
\hline 60 & 98 & 98 & 98 & 97 & 98 & 99 & 97 & 94 \\
\hline
\end{tabular}

Table 4 shows the number of cows per days open class in the Top 200 ranking (the 200 cows with the highest predicted breeding values) for 305-day cumulative milk yield and milk persistency. No significant difference between the models with and without the effect of pregnancy was observed for cumulative milk yield in either breed. On the other hand, significant differences between the two models were found for milk persistency, with the model including the effect of pregnancy showing larger numbers of cows with shorter days open and smaller numbers of cows with longer days open, when compared to the model without the effect of pregnancy. This result was significant for the Dairy Gyr breed, with the number of cows with days open longer than 270 days or of nonpregnant cows, being $38 \%$ lower for the model with the effect of pregnancy when compared to the model not including this effect, and with the number of cows with days open of 61 to 120 days being $50 \%$ higher. Therefore, the model including the effect of pregnancy overestimates the predicted breeding value for persistency of pregnant cows and underestimates breeding values of nonpregnant cows. These results agree with those reported by Bohmanova et al. (2009) for Canadian Holstein cows.

Table 4. Number of cows per days open class in the Top 200 ranking (the 200 cows with the highest predicted breeding values) for 305-day cumulative milk yield (305-day yield) and persistency of milk yield (Persistency) using the models with (EP) or without (WEP) the effect of pregnancy for genetic evaluation of the animals.

\begin{tabular}{|c|c|c|c|c|c|c|c|c|}
\hline \multirow[t]{3}{*}{ DOC } & \multicolumn{4}{|c|}{ Dairy Gyr } & \multicolumn{4}{|c|}{ Holstein } \\
\hline & \multicolumn{2}{|c|}{ 305-day yield } & \multicolumn{2}{|c|}{ Persistency } & \multicolumn{2}{|c|}{ 305-day yield } & \multicolumn{2}{|c|}{ Persistency } \\
\hline & WEP & EP & WEP & EP & WEP & EP & WEP & $\mathrm{EP}$ \\
\hline $\mathrm{DO}_{<60}$ & 1 & $1(0)$ & 4 & $4(0)$ & 17 & $20(+3)$ & 15 & $23(+8)$ \\
\hline $\mathrm{DO}_{61-90}^{\leq 60}$ & 22 & $21(-1)$ & 12 & $19(+7)$ & 50 & $49(-1)$ & 57 & $61(+4)$ \\
\hline $\mathrm{DO}_{91-120}^{61-90}$ & 34 & $34(0)$ & 14 & $21(+7)$ & 44 & $43(-1)$ & 36 & $33(-3)$ \\
\hline DO & 16 & $18(+2)$ & 22 & $26(+4)$ & 27 & $24(-3)$ & 26 & $23(-3)$ \\
\hline $\mathrm{DO}_{151-180}^{121-150}$ & 22 & $22(0)$ & 21 & $24(+3)$ & 10 & $10(0)$ & 19 & $15(-4)$ \\
\hline $\mathrm{DO}_{181-210}^{151-180}$ & 13 & $13(0)$ & 23 & $22(-1)$ & 13 & $13(0)$ & 8 & $7(-1)$ \\
\hline $\mathrm{DO}_{211-240}^{181-210}$ & 12 & $12(0)$ & 14 & $15(-1)$ & 7 & $9(+2)$ & 7 & $7(0)$ \\
\hline $\mathrm{DO}_{241-270}^{211-240}$ & 18 & $17(-1)$ & 21 & $19(-2)$ & 9 & $9(0)$ & 5 & $5(0)$ \\
\hline $\mathrm{DO}_{>270^{*}}^{241-2 / 0}$ & 62 & $62(0)$ & 69 & $50(-19)$ & 23 & $23(0)$ & 27 & $26(-1)$ \\
\hline
\end{tabular}

$\mathrm{DOC}=$ days open class. $\mathrm{DO}_{>270^{*}}$ includes cows with days open longer than 270 days or nonpregnant cows. Change in number of cows compared with model WEP is shown in parentheses. 
Livestock records regarding artificial insemination or controlled mating, including the date of their occurrence, are collected at the national level (registered animals) for the two breeds by the responsible breeder associations. However, the accuracy of these records is low. Therefore, prior adjustment of the data for the effect of pregnancy using adjustment factors as recommended by Bohmanova et al. (2009) is more appropriate than the inclusion of the effect in the genetic evaluation model, since adjustment factors can be estimated from a subset of data with validated conception dates. These factors would be more accurate than those estimated from the complete data set, in which the conception date would be approximated for some animals (Bohmanova et al., 2009).

Efforts should be made by breeder associations to increase the awareness of their associates about the importance of the systematic collection and transmission of livestock data regarding reproduction in their herds.

\section{CONCLUSION}

The inclusion of the effect of pregnancy in genetic evaluation models for these populations did not decrease residual variance, did not alter genetic parameter estimates and did not affect the ranking of cows and sires, based on their predicted breeding values for 305-day cumulative milk yield. In contrast, for persistency of milk yield, the lack of adjusting for the effect of pregnancy overestimates breeding values of nonpregnant cows or cows with long days open and underestimates breeding values of cows with short days open. Therefore, the lack of inclusion of the effect of pregnancy in genetic evaluation models implies errors in the selection of superior animals since it affects the ranking of animals for this trait. Models including the effect of days of pregnancy are recommended for the estimation of adjustment factors for the effect of pregnancy in national genetic evaluations of Dairy Gyr and Holstein cattle in Brazil.

\section{ACKNOWLEDGMENTS}

Research supported by Fundação de Amparo à Pesquisa do Estado de São Paulo (FAPESP - Brazil), Conselho Nacional de Desenvolvimento Científico e Tecnológico (CNPq Brazil) and Fundação de Amparo à Pesquisa do Estado de Minas Gerais (FAPEMIG - Brazil).

\section{REFERENCES}

Akers RM (2006). Major advances associated with hormone and growth factor regulation of mammary growth and lactation in dairy cows. J. Dairy Sci. 89: 1222-1234.

Bachman KC, Hayen MJ, Morse D and Wilcox CJ (1988). Effect of pregnancy, milk yield, and somatic cell count on bovine milk fat hydrolysis. J. Dairy Sci. 71: 925-931.

Bohmanova J, Miglior F and Jamrozik J (2008). Estimates of the effect of pregnancy on production traits of Canadian dairy breeds. Available at [http://cgil.uoguelph.ca/dcbgc/Agenda0809/Pregnancy.pdf]. Accessed January 25, 2010.

Bohmanova J, Jamrozik J and Miglior F (2009). Effect of pregnancy on production traits of Canadian Holstein cows. $J$. Dairy Sci. 92: 2947-2959.

Brotherstone S, Thompson R and White IMS (2004). Effects of pregnancy on daily milk yield of Holstein-Friesian dairy cattle. Livest. Prod. Sci. 87: 265-269.

Erb RE, Goodwin MM, Morrison RA and Shaw AO (1952). Lactation studies: 1. Effect of gestation. J. Dairy Sci. 35: 224-233. 
Haile-Mariam M, Bowman PJ and Goddard ME (2003). Genetic and environmental relationship among calving interval, survival, persistency of milk yield and somatic cell count in dairy cattle. Livest. Prod. Sci. 80: 189-200.

Interbull (2010). National GES information. Available at [http://www-interbull.slu.se/national_ges_info2/framesida-ges. htm]. Accessed May 25, 2010.

Loker S, Miglior F, Bohmanova J, Jamrozik J, et al. (2009a). Phenotypic analysis of pregnancy effect on milk, fat, and protein yields of Canadian Ayrshire, Jersey, Brown Swiss, and Guernsey breeds. J. Dairy Sci. 92: 1300-1312.

Loker S, Miglior F, Bohmanova J, Schaeffer LR, et al. (2009b). Short communication: effect of preadjusting test-day yields for stage of pregnancy on variance component estimation in Canadian Ayrshires. J. Dairy Sci. 92: 2270-2275.

Meyer K (2007). WOMBAT: a tool for mixed model analyses in quantitative genetics by restricted maximum likelihood (REML). J. Zhejiang Univ. Sci. B 8: 815-21.

Olori VE, Brotherstone S, Hill WG and McGuirk BJ (1997). Effect of gestation stage on milk yield and composition in Holstein Friesian dairy cattle. Livest. Prod. Sci. 52: 167-176.

Roche JR (2003). Effect of pregnancy on milk production and bodyweight from identical twin study. J. Dairy Sci. 86: 777-783. 